\title{
Proposta de melhoria da qualidade da água de abastecimento, Rosário-Maranhão-
}

\section{Brasil}

\author{
Suggestion for progress water supply quality of Rosario-Maranhão-Brazil \\ Propuesta para mejorar la calidad del agua de suministro, Rosário - Maranhão-Brasil
}

Recebido: 25/12/2020 | Revisado: 26/12/2020 | Aceito: 30/12/2020 | Publicado: 03/01/2021

\author{
Tenório Enes Calvet Filho \\ ORCID: https://orcid.org/0000-0002-2687-0253 \\ Universidade Federal do Pará, Brasil \\ E-mail: tenorio.calvet@hotmail.com \\ Mariane Furtado Gonçalves \\ ORCID: https://orcid.org/0000-0002-2905-1480 \\ Universidade Federal do Pará, Brasil \\ E-mail: marianefg@ufpa.br
}

\begin{abstract}
Resumo
As águas superficiais e subterrâneas podem ser contaminadas durante sua captação, no tratamento ineficiente, na sua distribuição e nos reservatórios. Por este motivo, objetivou-se neste estudo caracterizar o abastecimento, o monitoramento e a qualidade da água de consumo humano do município de Rosário- MA, de forma que se tenha subsídios para novas tomadas de decisão e mudanças para melhoria da qualidade ambiental e da saúde da população, e também objetivou-se propor uma alternativa de tratamento de água. Para isso, realizou-se levantamento de dados sobre o abastecimento, qualidade e monitoramento da água municipal, através de quatro etapas: caracterização do sistema de abastecimento de água, análise dos procedimentos adotados, levantamento da qualidade da água dos poços e da água distribuída a população e intervenção para melhoria do sistema de abastecimento. Assim, constatou-se a presença de coliformes totais entre $11 \%$ a $32 \%$ das amostras coletas e a presença de E. coli de $3 \%$ a $9 \%$ das amostras dos poços variando entre os anos de 2007 e 2017. Na rede de distribuição, a maioria das amostras estavam em não conformidade com a legislação, apresentando coliformes totais entre 52,9\% a 100\% das amostras e E. coli de 13,33\% a 68,48\% das amostras. O monitoramento e a qualidade da água de consumo do município de Rosário- MA, não estão de acordo com a legislação, assim necessitando a execução de medidas corretivas, propostas neste trabalho.
\end{abstract}

Palavras-chave: Abastecimento de água; Monitoramento; Qualidade da água; Proposta de melhoria.

\begin{abstract}
The water may be contaminated in the capture of the aquatic resources or during the treatment, distribution and reservation. For this reason, the objective of this study was to characterize the supply, monitoring and quality of water for human consumption in the municipality of Rosário-MA, so that there is support for new decision-making and changes to improve environmental quality and population health, and also aimed to propose an alternative water treatment. For this, data were collected on the supply, quality and monitoring of municipal water, through four stages: characterization of the water supply system, analysis of the procedures adopted, survey of the quality of the water in the wells and of the water distributed to population and intervention to improve the supply system. Thus, the presence of total coliforms was found between $11 \%$ to $32 \%$ of the collected samples and the presence of E. coli from $3 \%$ to $9 \%$ of the well samples, varying between the years 2007 and 2017. In the distribution network, most of the samples were in non-compliance with the legislation, with total coliforms between $52.9 \%$ to $100 \%$ of the samples and E. coli from $13.33 \%$ to $68.48 \%$ of the samples. The monitoring and quality of drinking water in the municipality of Rosário-MA, are not in accordance with the legislation, thus requiring the implementation of corrective measures proposed in this work.
\end{abstract}

Keywords: Water potability; Monitoring; Water quality; Improvement proposal.

\section{Resumen}

Las aguas superficiales y subterráneas pueden contaminarse durante la captura, el tratamiento, la distribución y los reservorios ineficientes. Por tal motivo, el objetivo de este estudio fue caracterizar el suministro, monitoreo y calidad del agua para consumo humano en el municipio de Rosário-MA, para que exista apoyo para nuevas tomas de decisiones y cambios para mejorar la calidad ambiental y salud de la población, y también tuvo como objetivo proponer un tratamiento alternativo del agua. Para ello, se recolectaron datos sobre el suministro, calidad y monitoreo del agua municipal, a través de cuatro etapas: caracterización del sistema de abastecimiento de agua, análisis de los procedimientos adoptados, relevamiento de la calidad del agua en los pozos y del agua distribuida a población e 
intervención para mejorar el sistema de abastecimiento. Así, la presencia de coliformes totales se encontró entre el $11 \%$ al $32 \%$ de las muestras recolectadas y la presencia de E. coli del 3\% al 9\% de las muestras de pozos, variando entre los años 2007 y 2017. En la red de distribución, la mayoría de las muestras no cumplían con la legislación, con coliformes totales entre $52,9 \%$ a $100 \%$ de las muestras y E. coli de $13,33 \%$ a $68,48 \%$ de las muestras. El monitoreo y la calidad del agua potable en el municipio de Rosário-MA, no están de acuerdo con la legislación, por lo que se requiere la implementación de las medidas correctivas propuestas en este trabajo.

Palabras clave: Abastecimiento de agua; Supervisión; Calidad del agua; Propuesta de mejora.

\section{Introdução}

De acordo com os dados da Organização Mundial da Saúde ainda existe cerca de 1,1 bilhões de pessoas sem acesso a água potável (WHO, 2013). Já o Brasil apresenta 12\% da água potável, mas esta tem sido contaminada por causa dos processos de urbanização, industrialização e de produção agrícola que faz com que a população tenha acesso a uma água que não está dentro dos padrões de qualidade ou que não tenha acesso devido a indisponibilidade de mananciais e sistemas de abastecimento adequados (Augusto et al., 2012; Mazepa, 2012).

Ao que se refere às fontes de captação de água no Brasil, de acordo com a última pesquisa realizada pelo Instituto Brasileiro de Geografia e Estatística (IBGE, 2010), estima-se que 42\% das captações são realizadas em mananciais superficiais e cerca de $57 \%$ são realizadas em mananciais subterrâneos e apenas $1 \%$ é realizado em outro tipo de captação.

O Sistema de Informação da Atenção Básica (SIAB) do Ministério da Saúde que apresenta 32,3 milhões de famílias brasileiras cadastradas em 2013, abrangendo 111,6 milhões de pessoas ou aproximadamente 57,6\% da população brasileira, afirma que 77,6\% dos domicílios apresentam rede de abastecimento. Segundo este mesmo sistema de informação, 13.763.543,41 mil m³ de água foi disponibilizada para consumo no ano de 2013, sendo que $10.821 .007,86 \mathrm{mil} \mathrm{m}^{3}$ foram tratadas em Estações de Tratamento de Água e 2.528.261,05 mil m³ foi tratada apenas por simples desinfecção.

Em 12 de dezembro de 2011, a Portaria no 518 foi atualizada pela no 2.914 do Ministério da Saúde, sendo ela mais completa em relação aos parâmetros microbiológicos e químicos, com linguagem mais simples para facilitar a compreensão e foi introduzida a proposta de um controle baseado nos preceitos do Plano de Segurança da Água (PSA). E em 28 de setembro de 2017 as informações e parâmetros de potabilidade foram incluídos na Portaria de Consolidação n 5 que consolida as normas sobre as ações e os serviços de saúde do Sistema Único de Saúde, estando mais precisamente no anexo XX que define os procedimentos de controle e da vigilância da qualidade da água para consumo humano e seu padrão de potabilidade. Desta forma, a legislação destaca os parâmetros necessários para água destinada ao consumo humano e determina que está sujeita a vigilância da qualidade. Ou seja, são designados valores máximos permitidos para cada parâmetro de qualidade da água de consumo humano (Brasil 2011; Ministério Da Saúde, 2017).

De acordo com a Diretriz Nacional de Plano de Amostragem da Vigilância da Qualidade da água para consumo humano do Ministério da Saúde (2016), a concentração mínima de cloro residual livre estabelecida no padrão potabilidade é de no mínimo $0,20 \mathrm{mg} / \mathrm{L}$ em toda a extensão do sistema de distribuição (reservatório e rede) como prevenção a uma possível (re)contaminação e/ou à proliferação de microrganismos no sistema de distribuição e não pode ficar com concentração acima de 5,0 mg/L. A turbidez, de acordo com a Portaria 2.914 de 2011 consolidada pela Portaria nº 5, apresenta valor máximo permitido 1,0 uT em 95\% das amostras quando passam por desinfecção no caso de água subterrâneas, 0,5 uT em 95\% das amostras quando passam por filtração rápida e 1,0 uT em 95\% das amostras em filtração lenta. E no caso dos fluoretos não pode ultrapassar $1,5 \mathrm{mg} / \mathrm{L}$.

Esta pesquisa faz-se necessária devido à realização do processo de monitoramento da qualidade da água captada no município de Rosário - MA, a qual permitiu se verificar os gargalos do sistema de captação, possibilitando melhorias nos processos, e consequentemente realizando uma caracterização sobre a extensão e severidade da degradação dos recursos 
hídricos subterrâneos utilizados para o abastecimento e os riscos na saúde da população do município.

Assim, objetiva-se neste estudo caracterizar o abastecimento, o monitoramento e a qualidade da água de consumo humano do município de Rosário de forma que se tenha subsídios para novas tomadas de decisão e mudanças para melhoria da qualidade ambiental e da saúde da população, assim como propor uma alternativa de tratamento de água.

\section{Metodologia}

O município de Rosário localiza-se na Mesorregião Norte Maranhense, Microrregião do Itapecuru Mirim, situando-se à margem esquerda do rio Itapecuru nas coordenadas geográficas 0256'12,6” S-044¹4'51,6” W, cerca de 70 Km de São Luis, 12 Km de Bacabeiras, 37 Km de Santa Rita e 25 Km de Axixá. Rosário faz parte da Região do Baixo Munim juntamente com os municípios: Axixá, Bacabeiras, Cachoeira Grande, Icatu, Morros, Presidente Juscelino e Santa Rita (Abdalla et al., 2010; Mesquita Neto, 2010; Dos Santos, 2011) (Figura 1).

Segundo os dados do IBGE, o Município de Rosário apresenta 39.576 habitantes no último censo, sendo que 23.258 $(58,76 \%)$ distribuídos na zona urbana e 16.324 (41,24\%) na zona rural e foi estimado 42.314 habitantes para o ano de 2017 . No entanto, dados mais atuais da Vigilância Sanitária e Funasa destacam uma população de 42.016 habitantes no ano de 2017.

A pesquisa realizada foi do tipo qualitativa. Qualitativa, pois foi utilizada pesquisa documental sobre os poços que abastecem o município de Rosário, cujo os dados coletados foram preferencialmente descritivos (Pereira et al., 2018). Além disso, realizou-se pesquisa participante, por meio de pesquisa em campo (condições do meio não controláveis ou com pouco controle, uma vez que a quantidade de variáveis é maior) e pesquisa laboratorial (condições do meio controladas para realização da experiência) para realizar a avaliação dos procedimentos de coleta, acondicionamento, transporte e análise de amostras de água dos poços de abastecimento do município de Rosário, no Estado do Maranhão, mostrados na Figura 1.

Foi realizada ainda pesquisa ação através de uma ação de intervenção para resolução dos problemas observados durante a avalição dos procedimentos de monitoramento da água do abastecimento.

Figura 1 - Localização dos poços ativos da sede do município de Rosário-MA.

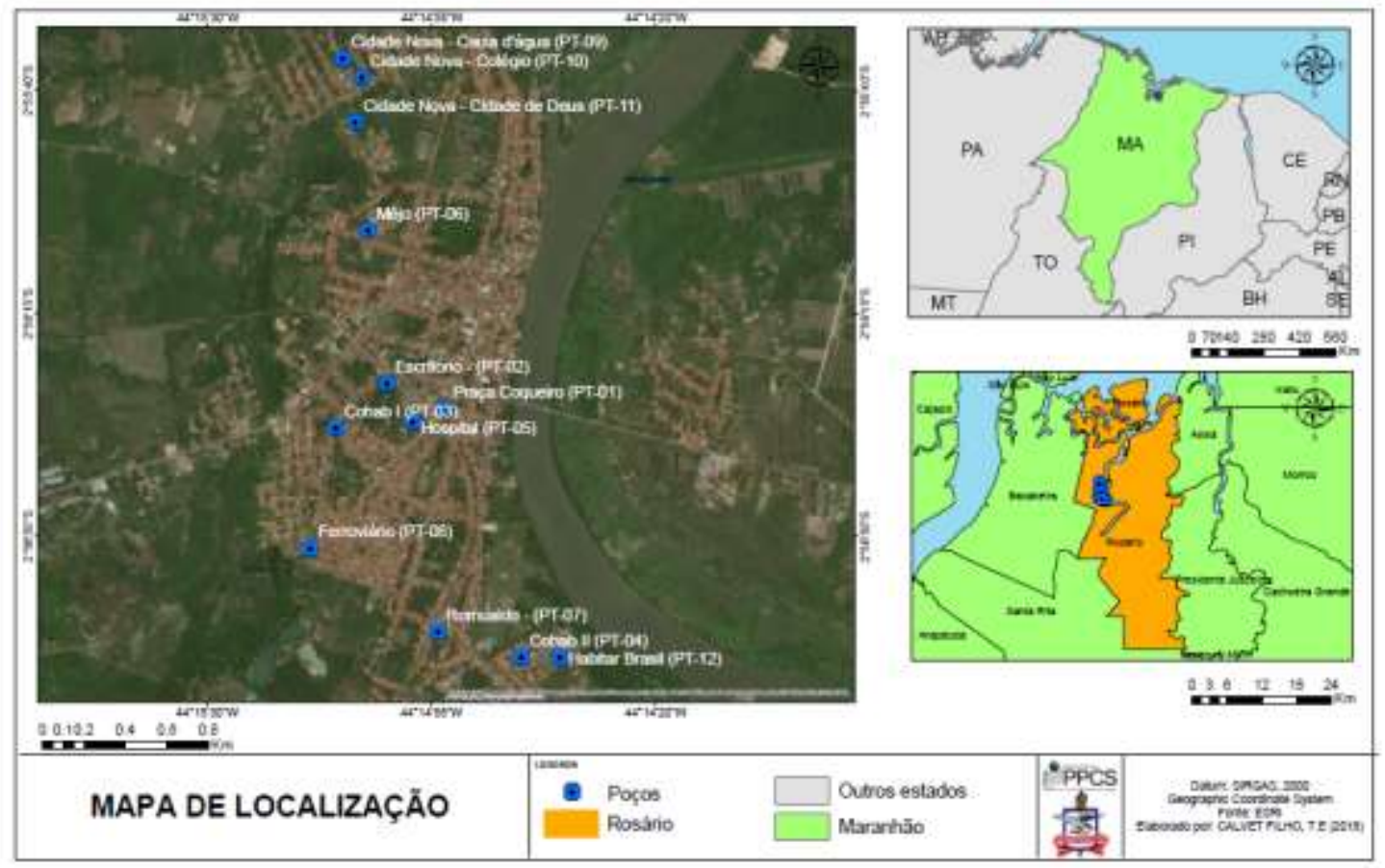

Fonte: ESRI elaborado por Calvet Filho (2018), 
Foi destacado pela Agência Nacional das Águas- ANA (2009) e por Mesquita Neto (2010) que o sistema de abastecimento do município de Rosário não apresentava estrutura adequada, e que deveria ser ampliado e melhorado através da construção de um novo sistema de abastecimento que adotasse o processo de desinfecção e que o mesmo fosse composto por uma nova rede com captação, adutora, elevatórias e sistema de desinfecção, entretanto a estrutura persiste a mesma e tem o manancial subterrâneo com fonte principal do sistema. Ainda na Figura 2, pode-se observar na localização dos 12 (doze) poços ativados.

Estes poços são identificados de PT-1, à PT-12, como mostrado na Tabela 1. Nesta tabela pode-se observar a vazão (1/h); a profundidade (m); o nível dinâmico (m) que é a profundidade do nível da água dentro do poço, quando está em bombeamento; e o nível estático $(\mathrm{m})$, sem bombeamento.

Esta pesquisa foi realizada em quatro etapas, como mostrado na Figura 2. A etapa de caracterização do sistema de abastecimento de água caracterizou-se pela busca de dados sobre o abastecimento de água da cidade de Rosário em documentos disponibilizados pelo Serviço Autônomo de Água e Esgoto (SAAE).

Levantou-se dados sobre a quantidade de água nos poços que abastecem a área estudada, população que é abastecida, profundidade dos poços, vazão, nível estático, nível dinâmico, quantidade de domicílios abastecidos, e quantidade de poços desativados.

Tabela 1 - Caracterização dos poços de abastecimento do município de Rosário-MA.

\begin{tabular}{|c|c|c|c|c|c|}
\hline Poços & & $\begin{array}{l}\text { Vazão } \\
\text { (litros/hora) }\end{array}$ & $\begin{array}{l}\text { Profundidade } \\
\text { (metros) }\end{array}$ & $\begin{array}{l}\text { Nível } \\
\text { Dinâmico } \\
\text { (metros) }\end{array}$ & $\begin{array}{l}\text { Nível Estático } \\
\text { (metros) }\end{array}$ \\
\hline Praça do Coqueiro & PT-1 & 23.468 & 93 & 62 & 42 \\
\hline Escritório & PT-2 & 23.620 & 93 & 50,39 & 58,42 \\
\hline COHAB I & PT-3 & 23.040 & 87 & 68,42 & 53 \\
\hline COHAB II & PT-4 & 26.500 & 113 & 64,22 & 48,98 \\
\hline Hospital & PT-5 & 26.400 & 100 & 66,54 & 63,42 \\
\hline Mêjo & PT-6 & 57.600 & 100 & 60 & 40 \\
\hline Patetinha & --- & Desativado & 90 & 53,64 & 42,20 \\
\hline Romualdo & PT-7 & 32.100 & 105 & 59,50 & 46 \\
\hline Ferroviário & PT-8 & 18.000 & 150 & 56,47 & 45,44 \\
\hline 13 de maio & --- & Desativado & 59 & - & - \\
\hline $\begin{array}{c}\text { Cidade Nova- Caixa } \\
\text { d'água }\end{array}$ & PT-9 & 10.800 & 80 & 46,16 & 33,45 \\
\hline Cidade Nova- Colégio & PT-10 & 28.800 & 82 & 45,56 & 35,14 \\
\hline Habitar Brasil & PT-11 & 5.520 & 89 & 51,25 & 51 \\
\hline $\begin{array}{c}\text { Cidade Nova- Cidade de } \\
\text { Deus }\end{array}$ & PT-12 & 9.500 & 90 & 65 & 43 \\
\hline
\end{tabular}

Fonte: SAAE Rosário (2018)

Posteriormente, realizou-se visitas a todos os poços para que houvesse a marcação em GPS Garmin Etrex 30 da localização de cada manancial subterrâneo. Assim, esses dados serviram para a caracterização do abastecimento de água do município de Rosário. 
Figura 2 - Etapas da pesquisa.

\begin{tabular}{|c|c|}
\hline $\begin{array}{l}\text { Caracterizaçáo do } \\
\text { Sistema de } \\
\text { Abastecimento de Àgua }\end{array}$ & $\begin{array}{l}\text { - Levantamento de dados sobre o abastecimento de água } \\
\text { do municipio de Rosário }\end{array}$ \\
\hline $\begin{array}{l}\text { Analises dos } \\
\text { Procedimentos } \\
\text { Adotados }\end{array}$ & $\begin{array}{l}\text { - Análise dos procedimentos de monitoramento realizados } \\
\text { pelo Serviço Autónomo de Agua e Esgoto (coleta, } \\
\text { acondicionamento, transporte e análises das amostras de } \\
\text { agua dos poços de abastecimento) e cloração dos poços de } \\
\text { abastecimento água de Rosário. }\end{array}$ \\
\hline $\begin{array}{l}\text { Qualidade da Água dos } \\
\text { Poços e da Agua } \\
\text { Distribuida a Populaçå̀o }\end{array}$ & $\begin{array}{l}\text { - Levantamento de dados sobre a qualidade da água } \\
\text { obtidos na Vigilancia Sanitária do municipio, banco de } \\
\text { dados SISAGUA e FUNASA. }\end{array}$ \\
\hline $\begin{array}{l}\text { Intervenção para } \\
\text { melhoria do Sistema de } \\
\text { Abastecimento de Água }\end{array}$ & $\begin{array}{l}\text { - Intervenção para melhoria do monitoramento da } \\
\text { qualidade da água e procedimento de cloraçào dos } \\
\text { poços de abastecimento da área urbana do municipio } \\
\text { de Rosário Maranhào. }\end{array}$ \\
\hline
\end{tabular}

Fonte: Autores.

$\mathrm{Na}$ etapa de análises dos procedimentos adotados realizou-se uma avaliação de todo o processo de coleta, acondicionamento, transporte e análises das amostras de água que são utilizadas para o monitoramento da qualidade da água do município, através do acompanhamento do processo que é realizado pelo Serviço Autônomo de Água e Esgoto (SAAE) de Rosário.

Nesta etapa para análise da qualidade da água dos poços foi realizado o levantamento dos dados referentes a qualidade microbiológica e cloro residual da água dos poços de abastecimento do município de Rosário, no período de 2007 a 2017 no banco de dados da FUNASA.

\section{Coleta, acondicionamento e transporte das amostras de água}

Para o monitoramento da qualidade da água dos mananciais subterrâneos foi utilizado uma amostragem mensal, na qual uma vez ao mês são coletadas amostras na saída de cada poço utilizando materiais (frascos e sacos estéreis) e reagentes adequados para as análises. Além disto, foi levado para campo quantidades superiores de frascos e sacos para acondicionamento da água caso seja necessário a utilização para uma nova amostragem.

Antes da amostragem foi realizada a desinfecção da saída de água do poço para que seja realizada a coleta, na qual a saída é limpa com uma esponja e álcool, depois aberta a válvula e desprezada água por três minutos. Posteriormente a esse procedimento é realizada a coleta em sacos de $100 \mathrm{ml}$ para amostra para análise microbiológica e em seguida a coleta da amostra em frascos foscos de $500 \mathrm{ml}$ para análise físico-química, sendo uma amostra para cada tipo de análise e para cada poço, totalizando duas amostras por poço.

Para coletar a amostra foi realizada a desinfecção na saída de cada poço, após essa desinfecção houve um desprezo desta água durante três minutos, e em seguida a coleta da amostra da água poço em um saco de $100 \mathrm{ml}$, assim todas as amostras foram identificadas com: número da amostra; identificação do poço; data e hora da coleta.

Posteriormente a coleta das amostras, foi realizada a cloração dos poços com hipoclorito de cálcio, no qual é utilizado uma garrafa pet para lançar o hipoclorito sem diluir diretamente no poço, este procedimento é realizado de dois em dois dias.

Já para o monitoramento da água que é distribuída na rede, foram realizadas coletas em diversos pontos de distribuição (reservatório de distribuição, em torneiras antes da reservação, cavaletes de hidrômetros e ponto de captação) e intradomiciliar/predial (bebedouros e em torneiras após a reservação). E estas amostras foram coletadas e transportadas para 
Laboratório Central de Saúde Pública do Maranhão (LACEN), vinculado a Vigilância Sanitária, onde foram realizadas as análises microbiológicas e físico-química.

Em relação aos pontos negativos e/ou inadequados cometidos durante o procedimento de coleta, acondicionamento e transporte das amostras, foi verificado que a amostragem deveria apresentar quantidades mínimas e frequências específicas para cada parâmetro, porém, esta era realizada mensalmente sendo que segundo o anexo 12 e 13 da Portaria de consolidação $\mathrm{n}^{\circ}$ 5 de 28 de Setembro de 2017 (Ministério Da Saúde, 2017) para análise microbiológica é necessário um mínimo de duas amostras semanais para os parâmetros coliformes totais e E. coli e a amostragem para análises físico-químicas como turbidez e concentração de cloro deve ser de duas amostras por semana já que deve ser coletada uma amostra duas vezes por semana. Porém, em Rosário o SAAE coleta apenas uma amostra mensal, um total de 12 amostras por ano, sendo uma quantidade bem menor do que o mínimo necessário.

Outro ponto observado o qual deve ser melhorado é a desinfecção por cloro dos poços, pois esta é realizada de forma inadequada, visto que não é feita uma diluição de hipoclorito na água do poço com a frequência esperada, não permanecendo na rede distribuição da água a concentração de cloro residual livre necessária. Desta forma, recomenda-se que a cloração seja realizada através de cloradores automáticos (bombas dosadoras de cloro), para que a cloração seja realizada de hora em hora, de acordo com a vazão de cada poço, gerando assim cloro residual, e desta forma se enquadrando de acordo com padrão da legislação.

Observou-se também que as condições do laboratório do SAAE, são desfavoráveis a realização das análises, visto que o laboratório necessita de equipamentos multiparâmetros, de melhoria na estrutura laboratorial, e ainda equipamentos para realização das análises, evitando-se assim redireciona-las ao laboratório em São Luís- MA.

Como o SAAE não tem estrutura para realização das análises das amostras, elas são transportadas para a Divisão de Engenharia de Saúde Pública no Laboratório de Controle e Qualidade de Água da Fundação Nacional de Saúde (FUNASA) para análise de poços e para o LACEN, para análise da rede de distribuição. No Laboratório de Controle e Qualidade de Água da Fundação Nacional de Saúde (FUNASA) são realizadas as análises microbiológicas e físico-químicas.

Todas as análises foram realizadas em laboratório, sendo que algumas das físico-químicas poderiam ser realizadas em campo, como por exemplo, a temperatura, a cor, condutibilidade, turbidez, pH, alcalinidade, ou no Laboratório do SAAE e enviado para a FUNASA para realização apenas os parâmetros que não fosse possível realizá-los, porém a falta de estrutura e equipamentos no laboratório do SAAE impossibilita.

\section{Análise Físico-química e microbiológica}

Apresenta o diagnóstico das análises físico-químicas e microbiológicas das águas dos poços que é realizada pela FUNASA e das águas no sistema distribuição que é realizada pelo Laboratório Central de Saúde Pública do Maranhão (LACEN) utilizado pela vigilância sanitária.

Os parâmetros físico-químicos realizados no laboratório da FUNASA foram a turbidez, temperatura, alcalinidade, pH, cor, condutibilidade e sólidos totais dissolvidos e os parâmetros microbiológicos são coliformes totais e termotolerantes (Escherichia coli) de acordo com Standard Methods for the Examination of Water and Wastewater 22a edição (2012). Nas análises microbiológicas foi utilizado o substrato cromogênico (colinert) no saco coletor que apresentava tiossulfato de sódio a $10 \%$ e água, no qual após vinte quatro horas de incubação em estufa a 35,0 \pm 0,5 a amostra muda de cor para amarelo alaranjado quando há presença de coliformes totais na amostra, essa cor é provocada pela presença da enzima $\beta$-galactosidase ao metabolizar o nutriente ONPG (orto-nitrofenil-ß-D-galactopiranisídeo), após o período de incubação.

Quando a amostra é colocada em contato com uma lâmpada ultravioleta $365 \mathrm{~nm}$ pode apresentar cor branco leitoso 
em decorrência da fluorescência azul no frasco amarelo quando positivo para E.coli (Escherichia coli) causada pela atividade da enzima ß-glucuronidase para metabolizar o substrato fluorogênico MUG (4-metilumbeliferil-ß-Dglicuronídeo). Quando a amostra permanece transparente o resultado é negativo para coliformes totais e para E. coli. Já para análises físico-químicas são utilizados multiparâmetros, clorimetros, reagentes químicos e turbidímetro.

As amostras coletadas pela Vigilância Sanitária foram analisadas no Laboratório Central de Saúde Pública do Maranhão (LACEN), em que foram realizadas as análises microbiológicas coliformes totais e termotolerantes (E. coli) e físicoquímicas (cor, turbidez, pH e cloro residual). Estes procedimentos não foram acompanhados, mas durante o levantamento de dados verificou-se que são estes parâmetros analisados pelo LACEN para o uso da Vigilância Sanitária.

Segundo a Diretriz Nacional do Plano de Amostragem da Vigilância da Qualidade da Água para Consumo Humano, os parâmetros que devem compor o plano de amostragem básico de rotina são: turbidez, cloro residual livre (ou outro composto residual ativo, caso o agente desinfetante utilizado não seja o cloro), coliformes totais/E. coli e fluoreto. Os quatro primeiros devido à importância como indicadores básicos da qualidade microbiológica da água para consumo humano, e o flúor por ser uma substância de incorporação obrigatória à água e devido ao seu significado de saúde (por deficiência ou excesso) (Ministério De Saúde, 2016a). Porém, a Vigilância Sanitária de Rosário realiza todas essas análises, exceto a análise de fluoreto.

Estes dados sobre estas análises são disponibilizados no Sistema de Informação de Vigilância da Qualidade da Água para Consumo Humano (SISAGUA) que é um instrumento do Programa Nacional de Vigilância da Qualidade da Água para consumo Humano (VIGIAGUA) que armazena os dados inseridos rotineiramente pelos profissionais do setor saúde (Vigilância) e pelos responsáveis pelos serviços de abastecimento de água (Controle) e permite a geração de relatórios sobre as formas de abastecimento utilizadas pela população e a respectiva qualidade da água consumida (Ministério Da Saúde, 2016b).

Em relação aos pontos negativos/ou inadequação em relação as análises, nenhum ponto negativo foi encontrado, pois o laboratório da FUNASA é muito bem equipado de alta complexidade e apresenta profissionais especializados. Todos esses procedimentos são grande importância para monitoramento e ações realizadas pela vigilância da qualidade da água, pois a Diretriz Nacional do Plano de Amostragem da Vigilância da Qualidade da Água para Consumo Humano (Ministério De Saúde, 2016a) afirma que é necessário considerar os recursos disponíveis, como rede de laboratórios, transporte para coleta de amostras, equipamentos para análises de campo, e, principalmente, a definição dos parâmetros a serem monitorados, respectivo número de amostras e frequência de amostragem para que sejam desenvolvidas ações de controle e saúde.

Portanto, quando foi avaliado o processo de coleta, acondicionamento, transporte e análises das amostras de água que são utilizadas para o monitoramento da qualidade da água do município de Rosário realizado pelo SAAE foi verificado que amostragem, a desinfecção da saída de água dos poços, as condições do laboratório e equipamentos do SAAE, o acondicionamento das amostras não foram realizadas de forma ideal, já os materiais para coleta utilizados pelo SAAE, as análises realizadas no laboratório da FUNASA, os equipamentos e materiais utilizados seguem a qualidade e o padrão proposto pela legislação.

\section{Qualidade da Água dos Poços e da Água Distribuída a População}

Na etapa da determinação da qualidade da água dos poços distribuída a população da cidade de Rosário foi realizado o levantamento de dados no SISAGUA (Sistema de Informação de Vigilância da Qualidade da Água para Consumo Humano) da Vigilância Sanitária (que utilizada o Laboratório Central de Saúde Pública do Maranhão- LACEN) no período de 2007 a 2017, em que os parâmetros de monitoramento podem ser observados na Tabela 2. 
Tabela 2 - Parâmetros para monitoramento de água de abastecimento público.

\begin{tabular}{|c|c|c|c|}
\hline Banco de Dados & Local & Ano & Parâmetros Analisados \\
\hline SAAE/FUNASA & Poços & $\begin{array}{c}2007 \mathrm{a} \\
2017\end{array}$ & $\begin{array}{c}\text { Coliformes Totais/ E. Coli/Cloro Residual/ } \\
\text { Turbidez/ Temperatura/ Alcalinidade/ pH/ } \\
\text { Condutibilidade/ STD }\end{array}$ \\
\hline $\begin{array}{l}\text { VIGILÂNCIA/SISAGUA/ } \\
\text { LACEN }\end{array}$ & $\begin{array}{c}\text { Rede de } \\
\text { distribuição }\end{array}$ & $\begin{array}{c}2007 a \\
2017\end{array}$ & $\begin{array}{c}\text { Coliformes Totais/ E. Coli/Cloro Residual/ } \\
\text { Turbidez/ pH/ Cor }\end{array}$ \\
\hline
\end{tabular}

Fonte: Autores.

Foram analisados dados da FUNASA entre os anos de 2007 a 2017 para analisar a qualidade da água dos poços que abastecem o município de Rosário. Porém, os anos de 2007 a 2013 não foram realizadas coletas para o monitoramento da físico-químico e de 2007 a 2014 para o monitoramento microbiológico. Outros dados disponíveis de coletas de monitoramento da qualidade do poço dataram de 1976 a 1999, sem haver uma frequência mensal ou padronizada.

Para a verificação da qualidade de água na distribuição do município de Rosário, também se analisou os dados da Vigilância entre os anos de 2007 a 2017. Em relação a quantidade de amostras das análises microbiológicas de coliformes totais verificou-se que nos anos de 2007, 2009 e 2010 não foram realizadas nenhuma coleta.

Como o abastecimento da Sede de Rosário é composto por 12 poços, é necessário que se utilize uma amostragem de um total de 24 amostras por semana, tanto para monitoramento de coliformes totais como para coliformes termotolerantes (E. coli). Ou seja, o anexo 13 do anexo XX da Portaria de consolidação no 5 de 28 de setembro de 2017 destaca que é necessário que sejam coletadas semanalmente duas amostras em cada manancial subterrâneo para monitoramento microbiológico (Ministério Da Saúde, 2017).

Desta forma, são necessárias 104 amostras por poço por ano, já que um ano tem 52 semanas, é obrigatória a coleta de no mínimo 1.248 amostras por ano, diante disso nenhum dos anos não foi coletado nem o mínimo de amostras necessárias.

Durante os anos coletou-se uma porcentagem de amostras muito pequenas referentes ao mínimo de amostras anuais prevista na legislação. Em 2015 coletou-se apenas 7\% de amostras, em 2016 coletou-se 8\% de amostras e no ano 2017 coletouse $10 \%$ do mínimo de amostras que deveriam ser coletadas, não chegando nos anos de 2015 e 2016 nem o mínimo da quantidade de amostras por poço (104 amostras).

Isto ocorreu devido SAAE, que é o responsável por coletar as amostras, realizar as coletas apenas uma vez ao mês e coletar uma amostra para cada parâmetro microbiológico, sendo que a frequência de acordo com o Ministério de Saúde (2017) deve ser semanalmente e duas amostras por parâmetro, ou seja, a amostragem e a frequência do monitoramento não estão sendo realizados em conformidade com a legislação.

Também se caracteriza como uma pesquisa quantitativa devido avaliar dados quantitativos de qualidade de água do município de Rosário dos bancos de dados da Vigilância Sanitária e da Fundação Nacional de Saúde- FUNASA. Além de utilizar dados referentes as amostras de água coletadas durante as campanhas do monitoramento.

A última etapa foi a intervenção através de uma pesquisa ação para resolução dos problemas observados durante a avalição dos procedimentos de monitoramento da água do abastecimento, na qual foram realizados treinamentos práticos de atualização e aperfeiçoamento para os funcionários com apoio da FUNASA durante o período de 26 a 28 de junho de 2017.

\section{Resultados}

O serviço de abastecimento de água e esgoto do município de Rosário é de responsabilidade da Prefeitura Municipal e é gerenciado pelo Serviço Autônomo de Água e Esgoto (SAAE). Segundo Medeiros (2008) este serviço é regulamentado pela 
Lei Municipal no 146 de 16 de janeiro de 1968.

De acordo com os dados do Serviço Autônomo de Água e Esgoto de Rosário o abastecimento do município é fornecido por um total de 48 poços sendo distribuídos na zona rural e zona urbana. A zona rural apresenta 34 poços, sendo que três estão desativados, 9 não tem arrecadação e 22 poços com arrecadação. Já a área urbana apresenta 14 poços, sendo que dois estão desativados, cujo os nomes são Patetinha e 13 de maio.

Estes poços são interligados e abastecem um total de 5.573 domicílios, sendo que destes 3.763 domicílios são abastecidos na área urbana e 1.810 domicílios na área rural. Desta forma, a maior percentual de domicílios abastecidos por esses poços encontram-se na área urbana (68\%) devido maior número de domicílios.

Baseando-se nesses dados, a área urbana do município de Rosário é abastecida por 14 poços, sendo que dois estão atualmente desativados, abastecem 3.763 domicílios, apresentam vazão de 5.520 a 57.600 litros/hora e profundidade de 59 a 150 metros. Estes poços são de responsabilidade da Prefeitura Municipal e são gerenciados pelo Serviço Autônomo de Água e Esgoto.

Nesses poços foram realizadas análises microbiológicas e físico-químicas. Para análise microbiológicas (coliformes totais e E. coli), somente os anos de 2015 à 2017 foram monitorados, e do total de amostras. A Figura 3 apresenta o número de meses em que não foram realizados os monitoramentos. Destaque-se que nos anos de 2015 e 2016 não houveram análises microbiológicas no ponto PT-11, e no ponto PT-12 somente no ano de 2015. Com essa análise foram obtidas 24\%, 32\% e $11 \%$ de amostras positivas para coliformes totais nos anos 2015, 2016 e 2017, respectivamente.

Em relação a porcentagem de amostras positivas para $E$. coli foram verificadas $3 \%$ de amostras positivas referentes as amostras coletadas no ano de 2015, $9 \%$ no ano de 2016 e $8 \%$ de amostras positivas no ano de 2017. Apresentando amostras com a presença significativa para estes dois parâmetros (Tabela 3; Figura 4).

Figura 3 - Número de meses em que não foi realizado monitoramento microbiológico.

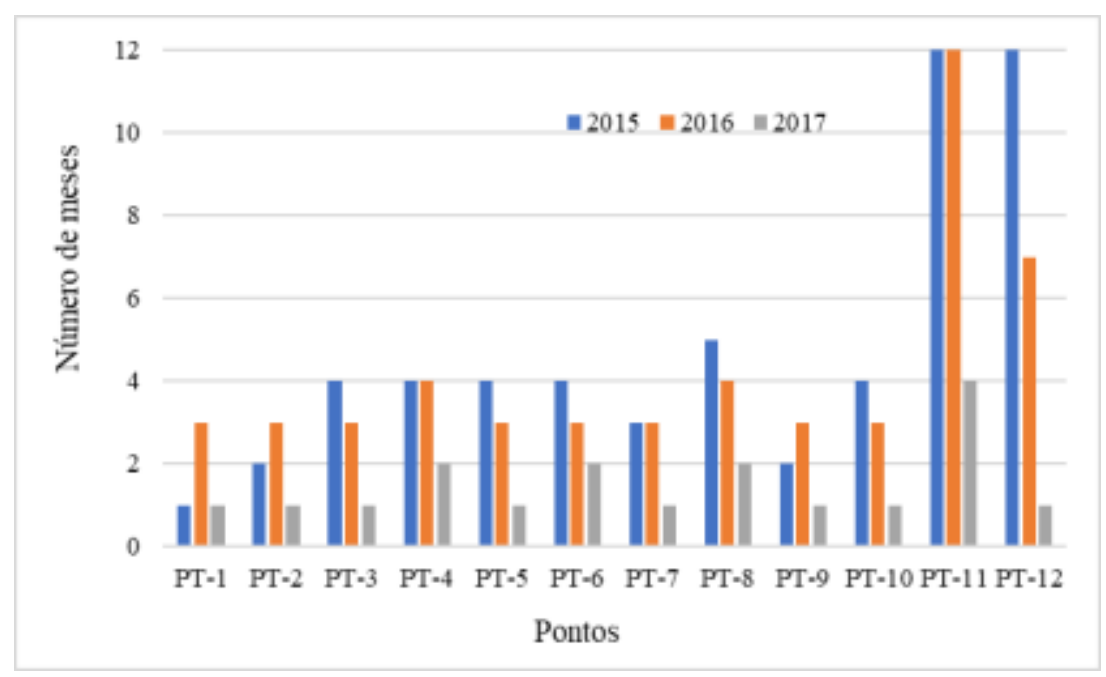

Fonte: Adaptado de FUNASA (2018) 
Tabela 3 - Presença de coliformes totais e E. coli nas amostras de água.

\begin{tabular}{cccccc}
\hline \multirow{2}{*}{ Ano } & $\begin{array}{c}\text { Total de amostras } \\
\text { coletadas de todos os } \\
\text { poços/ano }\end{array}$ & $\begin{array}{c}\text { Amostras com a presença } \\
\text { de coliformes totais em 100 } \\
\text { mL }\end{array}$ & $\begin{array}{c}\text { Amostras com presença } \\
\text { de } \boldsymbol{E} \text {. coli em 100 } \mathbf{~ m L}\end{array}$ \\
\cline { 2 - 6 } & 87 & 21 & 24 & $\mathbf{n}$ & \% \\
\hline 2015 & 97 & 31 & 32 & 9 & 3 \\
\hline 2016 & 126 & 14 & 11 & 10 & 8 \\
\hline 2017 & & & &
\end{tabular}

Fonte: FUNASA (2018).

Ainda na Figura 4, pode-se observar para cada poço monitorado (PT-1 à PT-2) a presença e a ausência de coliformes totais e E. Coli nas amostras de água.

Figura 4 - Presença e ausência de coliformes totais e E. coli.

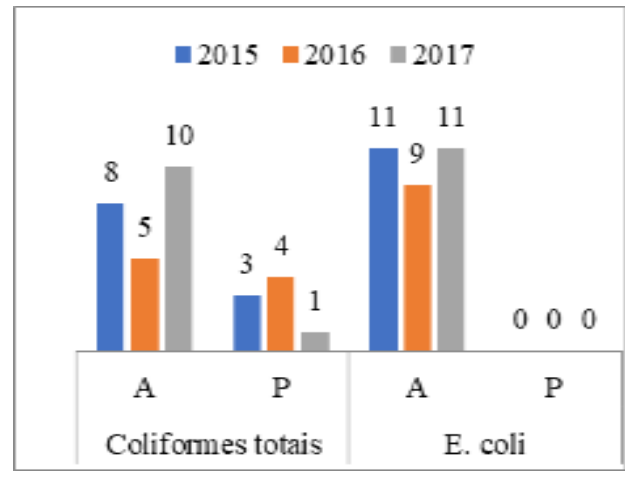

(a) PT-1

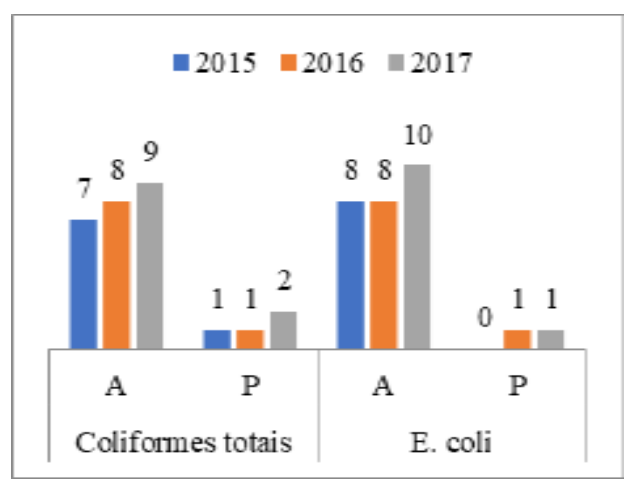

(c) PT-3

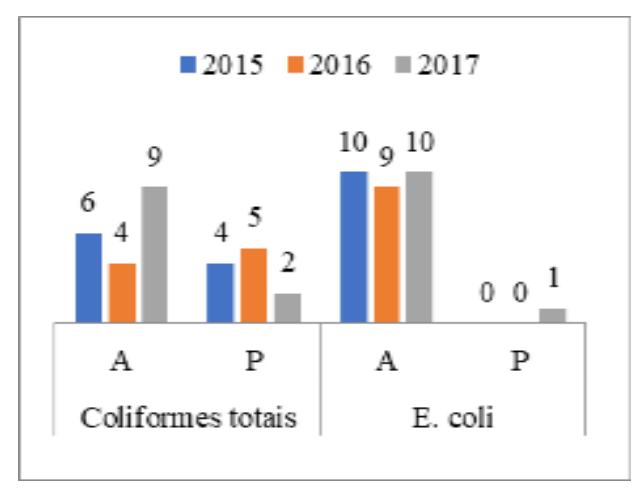

(b) PT-2

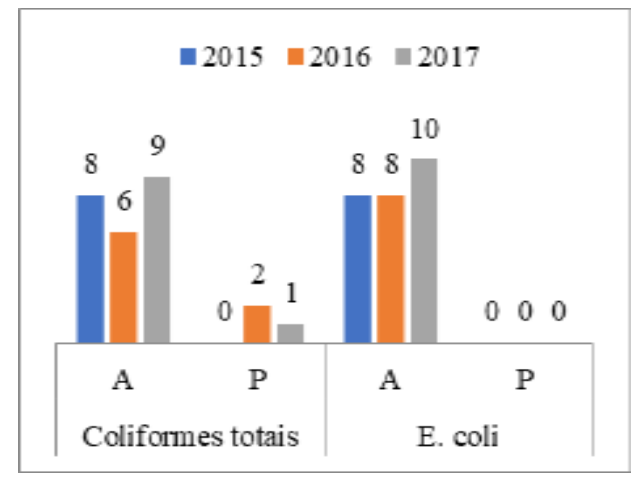

(d) PT-4 


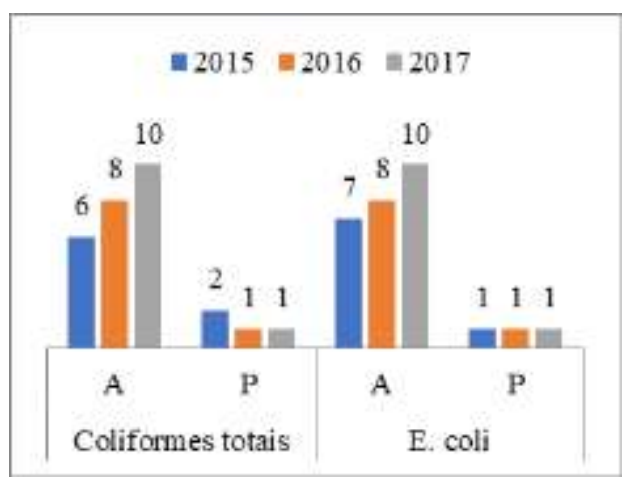

(e) PT-5

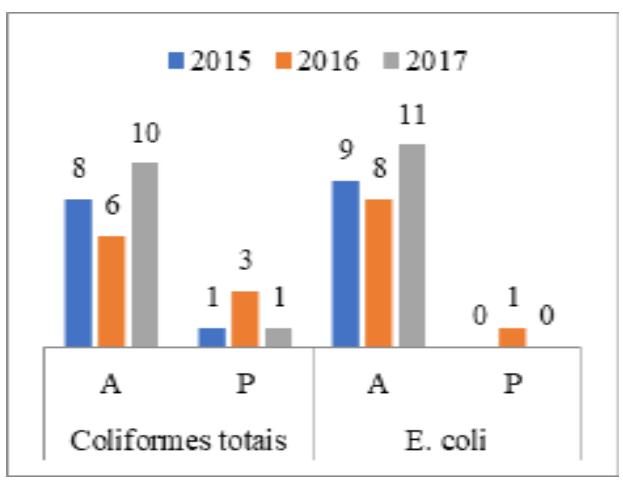

(g) PT-7

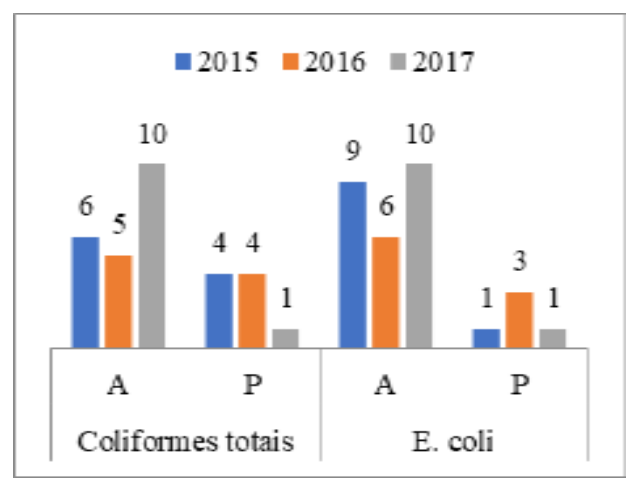

(i) PT-9

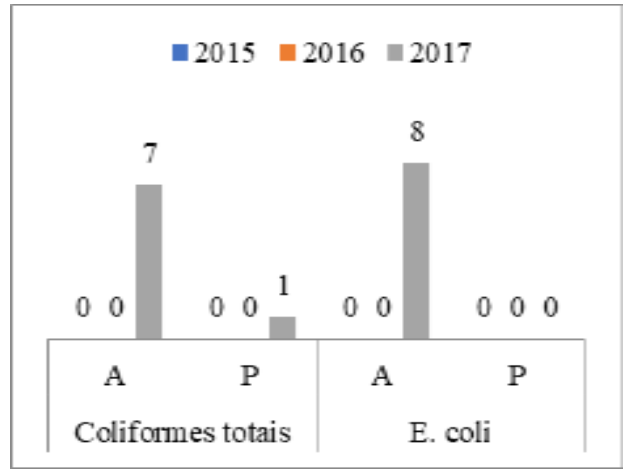

(k) PT-11

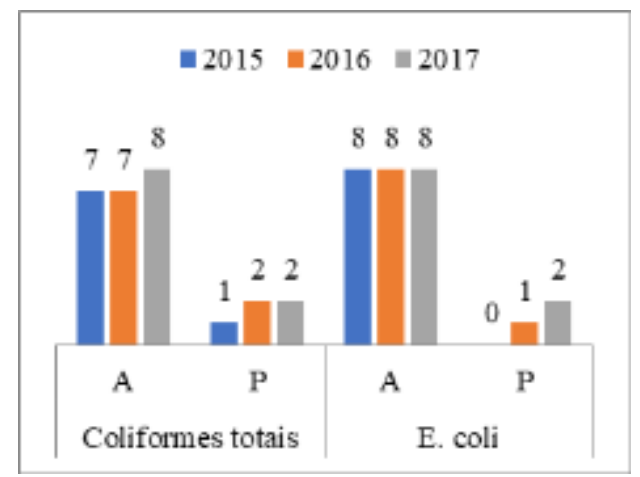

(f) PT-6

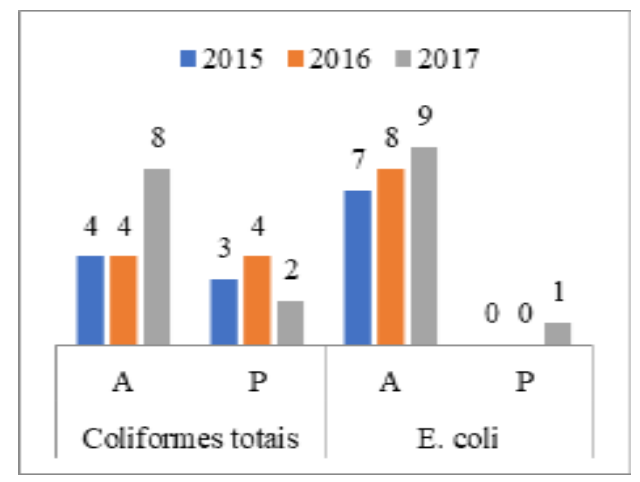

(h) PT-8

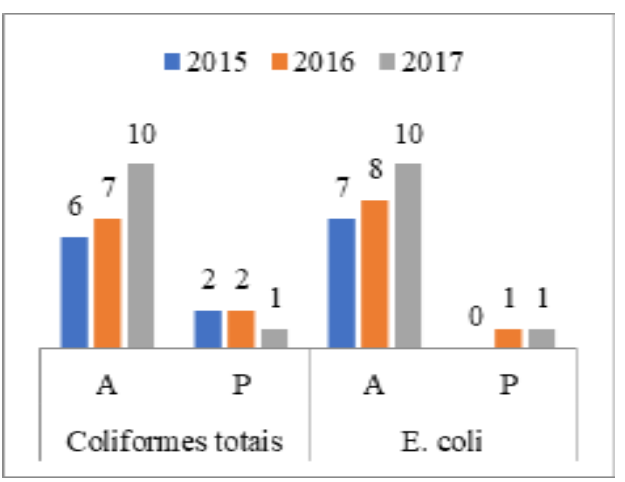

(j) PT-10

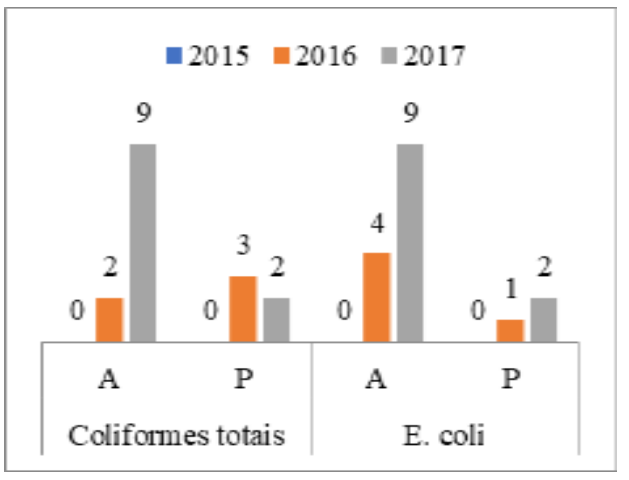

(1) PT-12

Fonte: Adaptado de FUNASA (2018) 
Com relação a presença de coliformes fecais todos os pontos havia presença deste microrganismo, exceto o ponto PT4 no ano de 2015. Somente os pontos de PT-1 e |PT-4 em todos os anos não houve presença de E. coli nas amostras de água analisadas.

Para a realização das análises físico-químicas, foi verificado que a quantidade de amostras coletadas para monitorar a turbidez foi maior que o mínimo no ano de 2017, porém não foi coletada nenhuma amostra em 2016 e apenas $75 \%$ de amostras que seriam obrigatórias em 2015.

Foi verificado que a amostragem de água para análise da concentração de cloro residual livre realizada pelo SAAE e analisada pelo laboratório da FUNASA foi pequena, não havendo amostragem na maioria dos anos, e nos anos em que foram realizadas as coletas o número de amostra foi muito pequeno, não chegando nem a 1\% (2015- 0,2\%; 2017- 0,6\%). Em relação a conformidade das amostras, $100 \%$ das amostras estavam em conformidade com a legislação em relação a turbidez, porém nenhuma amostra apresentou-se dentro dos padrões em relação ao cloro residual (Tabela 4).

Tabela 4 - Quantitativo de amostras e análises físico-químicas.

\begin{tabular}{|c|c|c|c|c|c|c|}
\hline \multirow{3}{*}{ Ano } & \multicolumn{6}{|c|}{ Cloro residual } \\
\hline & \multirow{2}{*}{$\begin{array}{l}\text { Total mínimo de } \\
\text { amostras } \\
\text { obrigatórias/poço }\end{array}$} & \multirow{2}{*}{$\begin{array}{c}\text { Total mínimo de amostras } \\
\text { coletadas de todos os } \\
\text { poços/ano }\end{array}$} & \multicolumn{2}{|c|}{$\begin{array}{l}\text { Total de amostras } \\
\text { coletadas de todos } \\
\text { os poços/ano }\end{array}$} & \multicolumn{2}{|c|}{$\begin{array}{l}\text { Total de amostras } \\
\text { em conformidade }\end{array}$} \\
\hline & & & $\mathbf{n}$ & $\%$ & $\mathbf{n}$ & $\%$ \\
\hline 2015 & 365 & 4380 & 9 & 0,2 & 0 & 0 \\
\hline 2016 & 365 & 4380 & 0 & 0 & 0 & 0 \\
\hline 2017 & 365 & 4380 & 13 & 0,3 & 0 & 0 \\
\hline \multicolumn{7}{|c|}{ Turbidez } \\
\hline 2015 & 12 & 144 & 9 & $6 \%$ & 9 & 100 \\
\hline 2016 & 12 & 144 & 0 & 0 & 0 & 0 \\
\hline 2017 & 12 & 144 & 13 & $9 \%$ & 13 & 100 \\
\hline
\end{tabular}

Fonte: FUNASA (2018).

Em relação a quantidade de amostras das análises microbiológicas de coliformes totais verificou-se que nos anos de 2007, 2009 e 2010 não foram realizadas nenhuma coleta e que no ano de 2008, 2013 e 2017 foi verificado percentuais muito baixos de 1,9\%, 30\% e 13,1\% de coletas em relação ao número mínimo, respectivamente, não chegando nem a metade do que se exigia.

Já os anos de 2014, 2015 e 2016 foram coletadas mais da metade do mínimo de amostras exigidas e o ano de 2011 realizou-se quase a quantidade obrigatória por ano $(96,15 \%)$. Então, na maioria dos anos a Vigilância Sanitária de Rosário realizou coletas de quantidades de amostras no sistema de distribuição abaixo do exigido pela legislação, muitas vezes não coletou nem o mínimo exigido de amostras por ano, com exceção do ano de 2013, no qual foram coletadas 172 amostras, $10 \%$ a mais de amostras do que o mínimo exigido.

Nos anos de 2008, 2011, 2012, 2013, 2014, 2015, 2016 e 2017 a maioria das amostras estavam em não conformidade apresentando coliformes totais presentes em 52,9\% das amostras a $100 \%$ das amostras, dependendo do ano. O ano que apresentou a presença de coliformes totais em todas as amostras foram 2008 e os anos de 2011, 2012, 2014, 2015 e 2016 apresentaram um percentual de contaminação microbiológica em mais de $70 \%$ das amostras.

Já os anos de 2013 e 2017 estavam presentes em mais de 50 \% das amostras (Tabela 5). Assim, pode-se afirmar que a presença de bactérias do grupo coliformes totais no sistema de distribuição (reservatórios e rede) pode indicar possíveis 
deficiências do processo de desinfecção, bem como do sistema de distribuição, indicando, por si só, a necessidade de investigação e execução de medidas corretivas.

Como verificou-se a presença de coliformes totais nas amostras exige-se a realização de análise específica para $E$. coli e foi verificado que houve a presença de $E$. coli nas amostras de todos os anos nos quais amostras foram coletadas. Mesmo que esse percentual tenha sido menor do que os coliformes totais, observou-se resultados bastante significativos principalmente no ano de 2013 com 68,48\% de amostras positivas (Tabela 5).

Verificou-se que nos anos de 2007, 2009 e 2010 da mesma forma que não foram coletadas amostras para monitoramento da qualidade microbiológica da água distribuída, também não foram coletadas amostras para análise físicoquímica (turbidez e cloro residual). E o ano de 2008 foram coletadas apenas três, sendo que nenhuma delas estava em conformidades com os parâmetros turbidez e cloro residual.

Em relação aos outros anos, comparando-se o total de amostras coletadas e o mínimo obrigatório apenas o ano de 2013 tanto para as análises de turbidez $(109,6 \%)$ e cloro residual $(110,2 \%)$ foram coletadas quantidades acima do mínimo obrigatório. O ano de 2011 apresentou um percentual de amostras significativas para os dois parâmetros (92,3\% e 95,51\%, respectivamente), mas não alcançou o mínimo. Os anos de 2008, 2012 e 2017 foi coletado um percentual de amostras bem baixos não chegando nem a $15 \%$ do mínimo obrigatório (Tabela 6).

Tabela 5 - Quantitativo de amostras e análises microbiológicas_ Vigilância Sanitária.

\begin{tabular}{ccccccccc}
\hline Ano & $\begin{array}{c}\text { População } \\
\text { (habitantes) }\end{array}$ & $\begin{array}{c}\text { Total mínimo } \\
\text { de amostras } \\
\text { obrigatórias }\end{array}$ & $\begin{array}{c}\text { Total de } \\
\text { amostras } \\
\text { coletadas }\end{array}$ & $\begin{array}{c}\text { Amostras com a } \\
\text { presença de } \\
\text { coliformes totais } \\
\text { em 100 mL }\end{array}$ & $\begin{array}{c}\text { Amostras com } \\
\text { presença de } \text { E. coli em } \\
\mathbf{1 0 0} \text { mL }\end{array}$ \\
\cline { 3 - 9 } & & $\mathbf{n}$ & $\mathbf{\%}$ & $\mathbf{n}$ & $\mathbf{\%}$ & $\mathbf{n}$ & \% \\
\hline 2007 & 35.432 & 144 & - & - & - & - & - & - \\
\hline 2008 & 39.103 & 156 & 3 & 1,9 & 3 & 100 & 1 & $33,33 \%$ \\
\hline 2009 & 39.631 & 156 & - & - & - & - & - & - \\
\hline 2010 & 39.576 & 156 & - & - & - & - & - & - \\
\hline 2011 & 39.631 & 156 & 150 & 96,15 & 107 & 71,33 & 41 & 38,32 \\
\hline 2012 & 40.030 & 156 & 48 & 30,77 & 34 & 70,83 & 9 & 26,47 \\
\hline 2013 & 40.030 & 156 & 172 & 110 & 92 & 52,9 & 63 & 68,48 \\
\hline 2014 & 40.983 & 156 & 94 & 60,26 & 75 & 79,78 & 27 & 36,00 \\
\hline 2015 & 41.349 & 168 & 93 & 55,36 & 74 & 79,56 & 35 & 47,30 \\
\hline 2016 & 41.964 & 168 & 101 & 60,12 & 71 & 70,29 & 15 & 21,13 \\
\hline 2017 & 42.016 & 168 & 22 & 13,1 & 15 & 68,18 & 2 & 13,33 \\
\hline
\end{tabular}

Fonte: Vigilância Sanitária de Rosário (2018).

Em relação aos outros anos, comparando-se o total de amostras coletadas e o mínimo obrigatório apenas o ano de 2013 tanto para as análises de turbidez $(109,6 \%)$ e cloro residual $(110,2 \%)$ foram coletadas quantidades acima do mínimo obrigatório. O ano de 2011 apresentou um percentual de amostras significativas para os dois parâmetros (92,3\% e 95,51\%, respectivamente), mas não alcançou o mínimo. Os anos de 2008, 2012 e 2017 foi coletado um percentual de amostras bem baixos não chegando nem a 15\% do mínimo obrigatório (Tabela 6).

Em relação a turbidez, a maioria dos anos apresentou as amostras em conformidade, de forma que os anos de 2012 , 2014 e 2017 apresentaram 100\% e os anos de 2011, 2013 e 2016 apresentaram 95\% ou mais de amostras coletadas dentro do 
padrão que é 1,0 uT em 95\% das amostras. Porém, em relação a concentração de cloro residual nas amostras, a maioria dos anos não apresentou conformidade em nenhuma amostra como nos anos de 2008, 2012, 2015, 2016 e 2017 e os outros anos apresentaram um percentual muito baixo de amostras com cloro residual livre.

Tabela 6 - Quantitativo de amostras e análises físico-químicas Vigilância Sanitária.

\begin{tabular}{|c|c|c|c|c|c|c|c|c|c|}
\hline \multirow{3}{*}{ Ano } & \multicolumn{5}{|c|}{ Turbidez } & \multicolumn{4}{|c|}{ Cloro residual } \\
\hline & \multirow{2}{*}{$\begin{array}{l}\text { Total mínimo } \\
\text { de amostras } \\
\text { obrigatórias }\end{array}$} & \multicolumn{2}{|c|}{$\begin{array}{c}\text { Total de } \\
\text { amostras } \\
\text { coletadas }\end{array}$} & \multicolumn{2}{|c|}{$\begin{array}{c}\text { Total de } \\
\text { amostras em } \\
\text { conformidade }\end{array}$} & \multicolumn{2}{|c|}{$\begin{array}{l}\text { Total de } \\
\text { amostras } \\
\text { coletadas }\end{array}$} & \multicolumn{2}{|c|}{$\begin{array}{l}\text { Total de amostras em } \\
\text { conformidade }\end{array}$} \\
\hline & & $\mathbf{n}$ & $\%$ & $\mathbf{n}$ & $\%$ & $\mathbf{n}$ & $\%$ & $n$ & $\%$ \\
\hline 2007 & 144 & - & - & - & - & - & - & - & - \\
\hline 2008 & 156 & 3 & 1,9 & 0 & 0 & 3 & 1,9 & 0 & 0 \\
\hline 2009 & 156 & - & - & - & - & - & - & - & - \\
\hline 2010 & 156 & - & - & - & - & - & - & - & - \\
\hline 2011 & 156 & 144 & 92,3 & 143 & 99,31 & 149 & 95,51 & 6 & 4,03 \\
\hline 2012 & 156 & 15 & 9,6 & 15 & 100 & 48 & 30,77 & 0 & 0 \\
\hline 2013 & 156 & 171 & 109,6 & 162 & 94,73 & 172 & 110,2 & 13 & 7,56 \\
\hline 2014 & 156 & 94 & 60,26 & 94 & 100 & 85 & 54,49 & 4 & 4,7 \\
\hline 2015 & 168 & 96 & 57,14 & 95 & 98,95 & 83 & 49,4 & 0 & 0 \\
\hline 2016 & 168 & 101 & 60,12 & 100 & 99 & 89 & 52,98 & 0 & 0 \\
\hline 2017 & 168 & 23 & 13,69 & 23 & 100 & 17 & 10,12 & 0 & 0 \\
\hline
\end{tabular}

Fonte: Vigilância Sanitária de Rosário (2018).

\section{Discussão}

O município de Rosário apresenta 12 poços que abastecem sua sede. Resultados diferentes, em relação a quantidade poços que abastecem o município de Rosário, foram encontrados na pesquisa de Mesquita Neto (2010). Ele afirma que o sistema de abastecimento de água na área urbana de Rosário é composto por uma bateria de 15 poços, não apenas 14 como foi encontrado nesta pesquisa. Isto deve ter ocorrido devido alguns poços no decorrer dos anos serem desativados.

Santos (2011) afirma que apesar do Maranhão apresentar dados que lhe favoreçam status de estado da federação com maior índice de crescimento em ligações prediais e dentre os estados da região nordeste com menor índice de municípios em fornecimento de água por formas alternativas, o que se percebe é que apesar de todo esse aumento de ligações prediais, muitos municípios assim como Rosário, ainda sofrem com a escassez de água de boa qualidade; a respeito de aumentar o percentual das ligações de água, sem, contudo atentar para a qualidade da água servida sendo um risco para a população.

Foi destacado pela Agência Nacional das Águas (2009) e por Mesquita Neto (2010) que o sistema de abastecimento do município de Rosário não apresentava estrutura adequada, e que deveria ser ampliado e melhorado através da construção de um novo sistema de abastecimento que adotasse o processo de desinfecção e que o mesmo fosse composto por uma nova rede com captação, adutora, elevatórias e sistema de desinfecção, entretanto a estrutura persiste a mesma e tem o manancial subterrâneo com fonte principal do sistema.

Segundo o Ministério da Saúde (2016) é necessário realizar monitoramento da qualidade da água para auxiliar no gerenciamento de riscos à saúde associados à qualidade da água destinada ao consumo humano, como parte integrante das ações de prevenção de agravos e de promoção da saúde, previstas no Sistema Único de Saúde. Esse monitoramento deve ser 
realizado nos poços e na rede de distribuição, sendo que em Rosário é realizada nos mananciais subterrâneos pelo Serviço Autônomo de Água e Esgoto (SAAE) e no sistema de abastecimento (na distribuição) pela Vigilância Sanitária.

Durante o monitoramento da qualidade de água dos poços, coletou-se uma porcentagem de amostras muito pequena quando se compara o mínimo de amostras anuais prevista na legislação. Isto ocorreu devido o SAAE, que é o responsável por coletar as amostras, realizar as coletas apenas uma vez ao mês e coletar uma amostra para cada parâmetro microbiológico, sendo que a frequência de acordo com o Ministério de Saúde (2017) deve ser semanalmente e duas amostras por parâmetro, ou seja, a amostragem e a frequência do monitoramento não estão sendo realizados em conformidade com a legislação.

$\mathrm{Na}$ pesquisa foi verificado que a amostragem de água para análise da concentração de cloro residual livre é bem pequena, não havendo amostragem na maioria dos anos e nos que apresentam coletas, o número de amostra é muito pequeno não chegando nem a $1 \%$ e para análise de turbidez apresentou amostragem ideal em alguns anos e outros nem foram realizadas coletas. De acordo com a Portaria de consolidação n 5 de 28 de setembro de 2017 é necessário realizar coleta de 1 amostra mensal para monitoramento da turbidez e 1 amostra diária de água para monitorar o cloro livre em mananciais subterrâneos (Ministério Da Saúde, 2017).

Em relação a qualidade água dos poços e na distribuição foi verificado que as amostras apresentaram-se com a presença significativa para coliformes totais e termotolerantes e baixa concentração de cloro residual em todos os anos que foram realizadas coletas não estando de acordo com a Portaria de consolidação no 5 de 28 de Setembro de 2017 estando de acordo apenas no parâmetro turbidez (Ministério Da Saúde, 2017).

A presença de E. coli ou de coliformes termotolerantes fornece evidência de contaminação fecal e sua detecção deve levar em consideração mais intervenção, que pode incluir mais amostragem e investigação de origens potenciais, tais como falhas na integridade do sistema de distribuição (Rasella, 2013).

De acordo com Ministério da Saúde (2017) a Portaria de Consolidação no 5 estabelece que a concentração mínima de cloro residual livre deve ser de $0,20 \mathrm{mg} / \mathrm{L}$, essa concentração deve estar presente na água em toda a extensão do sistema de distribuição (reservatório e rede) como prevenção a uma possível (re)contaminação e/ou à proliferação de microrganismos no sistema de distribuição. E em relação a níveis de cloro residual livre superiores a 2,0 mg/L, mesmo que não apresente riscos a saúde a população pode rejeitar devido à manifestação de gosto e odor na água, desta forma a concentração de cloro residual livre não deve ser superior a 5,0 mg/L.

Segundo a Diretriz Nacional do Plano de Amostragem da Vigilância da Qualidade da Água para Consumo Humano do Ministério da Saúde (2016a) quando houver valores de cloro residual livre inferiores a 0,20 mg/L podem indicar falhas no processo de desinfecção, consumo excessivo do cloro residual no sistema de distribuição ou necessidade de pontos secundários de cloração (recloração) devido a extensão da rede de distribuição. Então, estes dados referentes a nenhuma concentração de cloro residual livre ou percentual baixo nas amostras de água monitoradas pela Vigilância Sanitária de Rosário pode ser explicado pela maneira incorreta que estava sendo realizada a cloração dos poços de abastecimento, explicando também a elevada porcentagem de amostras positivas para coliformes totais e E. coli. Além disso, a contaminação que pode ocorrer durante o processo de distribuição e/ou reservação.

Assim, os procedimentos de cloração dos poços deveriam ser melhorados já que não estão sendo realizados de forma eficaz e são imprescindíveis já que o cloro tem alto poder eliminação de bactérias são oxidante sendo aplicado também nos processos de tratamento como controle do sabor e odor, prevenção de crescimento de algas, remoção de ferro e manganês, remoção de cor e controle do desenvolvimento de biofilmes em tubulações, assim sendo importante para assegurar a qualidade da água desde o tratamento até o consumo (Libânio, 2010).

Outras pesquisas também apresentam resultados semelhantes. Na pesquisa de Oliveira (2017) também foram 
verificadas quantidades de amostras coletadas e analisadas abaixo das exigidas durante o monitoramento da qualidade da água de São Luís e São José de Ribamar, também havendo problemas no planejamento, execução da amostragem e apresentando amostras que não estavam em conformidade com a legislação.

Bezerra (2016) pesquisou sobre a qualidade da água do município Campina Grande na Paraíba através da análise de 14 amostras do mês de fevereiro de 2016 disponibilizadas pela Vigilância Ambiental e obteve-se resultados insatisfatórios para os parâmetros Cor, pH, Turbidez, Coliformes totais e E. coli. Apresentando apenas uma amostra com a cor dentro do padrão, duas amostras com turbidez dentro do padrão, todas amostras com a presença de coliformes totais e E. coli estando todas fora do padrão e apenas o parâmetro pH estava dentro do padrão em todas as amostras. E também foi verificado na pesquisa de Alves et al. (2017) amostras fora dos padrões aceitáveis na maioria dos meses avaliados, principalmente nas análises microbiológicas, quando foram analisados os históricos das análises realizadas no ano de 2014 e 2015 pela Agência de Vigilância Ambiental da cidade de Juazeiro do Norte.

Resultados com amostras insatisfatórias em relação aos parâmetros físico-químicos e microbiológicos também foram encontrados por Barreto et al. (2015) quando analisaram dados coletados na rede estadual de laboratórios de Vigilância da Qualidade da Água da Bahia, apresentando 22\% de amostras fora do padrão da legislação. Assim como Pacheco et al. (2016) que encontraram $17 \%$ das amostras consideradas impróprias em poços de 23 municípios da Região do Vale do Rio Pardo no Rio Grande do Sul.

$\mathrm{Na}$ avaliação da qualidade das águas subterrâneas em poços de diversas regiões do estado do Ceará realizada por Costa et al. (2012) foi verificado que das 230 amostras analisadas $40 \%$ apresentaram crescimento de coliformes totais e $12,2 \%$ de E. coli. Mais recentemente também no Ceará, mais precisamente em Jamacaru distrito de Missão Velha, Carvalho et al. (2017) encontraram valores muito elevados de coliformes totais e E.coli em três pontos de coleta que podem ter sido causados devido a inexistência de Cloro na água, o qual é responsável pela desinfecção da mesma.

Valores mais elevados ainda foram encontrados por Silva et al. (2013) que verificaram a qualidade da água de poços rasos que abastecem o bairro Santa Felicidade em Curitiba no Paraná e obtiveram crescimento de coliformes totais em todas as amostras e $40 \%$ apresentaram E. coli.

Baseando-se nos dados analisados da FUNASA e da Vigilância Sanitária de Rosário tanto em relação a amostragem quanto a qualidade da água dos mananciais utilizados e da água no sistema de distribuição, verificou-se que não são ideais. Muitos são os problemas encontrados já que há poços que não são monitorados frequentemente e os que são monitorados a amostragem não é realizada como é exigido pela legislação. Além disso, a água que abastece Rosário é de má qualidade já que apresentam coliformes totais e termotolerantes e não é realizada uma cloração eficiente.

\section{Intervenção para Melhoria do Abastecimento de Água}

A análise integrada de banco de dados tanto da vigilância como do SAAE permitiu orientar a definição de algumas ações de intervenção e a identificação de problemas como amostras de água fora do padrão de potabilidade (em sistemas de abastecimento e poços) e do não cumprimento do plano de amostragem para o controle da qualidade da água e concentração de cloro residual livre, indicou a necessidade de atuação junto aos responsáveis por esses serviços.

Então, foi realizada uma intervenção através de uma pesquisa ação para resolução dos problemas verificados durante a avaliação dos procedimentos de monitoramento da água do abastecimento de Rosário. Esta intervenção foi primeiramente planejada juntamente com a FUNASA, na qual disponibilizou profissionais de controle da qualidade da água para ministrarem treinamentos práticos de atualização e aperfeiçoamento para os funcionários.

Os treinamentos tiveram como objetivo melhorar os procedimentos e rotinas de monitoramento da qualidade e 
cloração dos poços de abastecimento de Rosário, na qual foram realizadas coletas de amostras de água para o monitoramento microbiológico e físico-químico com o auxílio da Unidade Móvel de Controle de Qualidade da Água (UMCQA) da FUNASA durante o período de 26 a 28 de junho de 2017, demonstrado como devem ser realizados todos os processos de coleta, acondicionamento análise das amostras e cloração dos poços.

\section{Conclusão}

A pesquisa também serviu para verificar o status de qualidade da água de consumo nos mananciais e na distribuição. Sendo que apresentou amostragem com frequência e número de amostras abaixo do total mínimo exigidos para os parâmetros microbiológicos (coliformes totais e E. coli) e físico-químicos (turbidez e cloro residual livre). Foi verificado que há poços que não são monitorados e outros que apresentam uma baixa frequência de monitoramento, sendo que a amostragem não segue padrão exigido por lei.

Em relação a qualidade microbiológica, nos mananciais foi constatado a presença de coliformes totais em $11 \%$ a $32 \%$ das amostras e a presença de E. coli em 3\% a 9\% das amostras variando entre os anos; na rede de distribuição essa porcentagem aumentou de forma que a maioria das amostras estavam em não conformidade apresentando coliformes totais presentes em 52,9\% a 100\% das amostras e E. coli em 13,33\% a 68,48\% das amostras variando entre os anos.

Assim, pode-se afirmar que mesmo com uma amostragem ineficiente, pode-se constatar a presença de bactérias do grupo coliformes tanto nos poços como no sistema de distribuição. Isto ocorre devido a deficiência do processo de desinfecção (cloração) realizadas nos poços já que não há aparelho dosador de cloro e contaminação durante a distribuição, necessitando a execução de medidas corretivas, mais intervenção e verificação das falhas na integridade do sistema.

Então foi constatado que são necessárias ações de intervenções como a que foi realizada com o apoio da FUNASA e ações de fiscalização dos procedimentos de monitoramento, mudança dos protocolos de desinfecção da água nos mananciais e definidas estratégias de melhoria da qualidade da água e da saúde do município de Rosário- MA. E recomenda-se como trabalhos futuros a proposição de um manual de procedimentos de monitoramentos da qualidade da água dos poços, juntamente com a consolidação dos protocolos de desinfecção da água dos mananciais que abastecem a cidade.

\section{Referências}

Agência Nacional Das Águas (2007). A História do Uso da Água no Brasil. Do Descobrimento ao Século XX.

Alves W. S., Silva T. I., Marrom D. A. S., Santos T. M., \& Santos H. R. (2017). Avaliação da qualidade da água do abastecimento público do município de Juazeiro do Norte, CE. Revista Desafios 4(2).

Augusto, L. G. S., Gurgel, J. G. D., Neto, H. F. C., Melo, C. H., \& Costa, A. M. O (2012). Contexto global e nacional frente aos desafios do acesso adequado a água para consumo humano. Ciência e Saúde Coletiva, 17(6),1511-1522.

Barreto, R.L., Pedreira, M.M., \& Will, R.M. (2015). Monitoramento da qualidade da água para consumo humano no estado da Bahia no ano 2014. Revista Baiana de Saúde Pública, 39,31-40.

Bevilacqua P. D., Carmo R.F., Melo C. M., \& Bastos R. K. X. (2014). Vigilância da qualidade da água para consumo humano no âmbito municipal: contornos, desafios e possibilidades. Saúde Soc. São Paulo, 23(2), 467-483.

Bezerra, A. S. (2016). Vigilância ambiental em saúde relacionada à qualidade da água para consumo humano no município de Queimadas. 2016. 28f. Trabalho de Conclusão de Curso (Graduação em Química Industrial) Universidade Estadual da Paraíba, Campina Grande.

Decreto No 24.643, de 10 de julho de 1934. Decreta o Código de Águas. 1934.

Ministério da Saúde. Fundação Nacional de Saúde. Manual de controle da qualidade da água para técnicos que trabalham em ETAS. Fundação Nacional de Saúde. - Brasília. DF: Funasa 2014.

Ministério da Saúde. Estabelece os procedimentos e responsabilidades relativos ao controle e vigilância da qualidade da água para consumo humano e seu padrão de potabilidade, e dá outras providências. Diário Oficial da República Federativa do Brasil, Brasília. 2004. 
Research, Society and Development, v. 10, n. 1, e8810111496, 2021

(CC BY 4.0) | ISSN 2525-3409 | DOI: http://dx.doi.org/10.33448/rsd-v10i1.11496

Ministério da Saúde. Dispõe sobre os procedimentos de controle e de vigilância da qualidade da água para consumo humano e seu padrão de potabilidade, Brasília. 2011.

Companhia De Saneamento De Minas Gerais. Água não tratada é porta aberta para várias doenças. 2010.

Instituto Brasileiro De Geografia E Estátistica (IBGE) -. 2010. Censo Demográfico.

Libânio, M. (2010). Fundamentos de qualidade e tratamento de água. Campinas: Átomo.

Mazepa, H. H. S. (2012). Mapeamento da Qualidade da Água para Consumo Humano em Santa Catarina sob o olhar da Vigilância Sanitária. Florianópolis. Trabalho de Conclusão de Curso (Graduação em Engenharia Sanitária e Ambiental) - Universidade Federal de Santa Catarina, Florianópolis, 2012.

Mesquita Neto, M. C. (2010). Cenários do abastecimento de água na zona urbana do município de Rosário, Maranhão: um subsídio para a sustentabilidade no fornecimento de água. Dissertação apresentada ao Programa de Pós-Graduação em Sustentabilidade dos Ecossistemas, Universidade Federal do Maranhão, São Luís.

Ministério Da Saúde. Secretaria de Vigilância em Saúde. Departamento de Vigilância em Saúde Ambiental e Saúde do Trabalhador. Diretriz Nacional do Plano de Amostragem da Vigilância da Qualidade da Água para Consumo Humano [recurso eletrônico] / Ministério da Saúde, Secretaria de Vigilância em Saúde, Departamento de Vigilância em Saúde Ambiental e Saúde do Trabalhador. - Brasília: Ministério da Saúde, 2016.

Ministério Da Saúde. Portaria de Consolidação No 2, de 28 de setembro de 2017. Dispõe sobre a consolidação das normas sobre as políticas nacionais de saúde do Sistema Único de Saúde.

Oliveira, C. N., Nascimento S. A.M., \& Campos V. P. (2017). Análise comparativa de índices de qualidade da água subterrânea. XIX Congresso Brasileiro de Águas Subterrâneas.

Pacheco G., Costa A. B., Silveira E. O., Deprá B., \& Lobo, E. A. (2016). Calibração de um índice de qualidade de águas subterrâneas (iqnas) para a região do Vale do Rio Pardo, RS, Brasil: nova ferramenta tecnológica para o monitoramento ambiental. Águas Subterrâneas 30(3), $440-454$.

Pereira A.S. et al. (2018). Metodologia da pesquisa científica. [e-book]. Santa Maria. Ed. UAB/NTE/UFSM. https://repositorio.ufsm.br/bitstream/handle/1/15824/Lic_Computacao_Metodologia-Pesquisa-Cientifica.pdf?sequence=1

Pereira, L. D. A. (2012). De onde vem a água que nós bebemos? Revista Eletrônica de Ciências.

http://www.cdcc.sc.usp.br/ciencia/artigos/art_50/agua.html

Pinto-Coelho, R. M., \& Havens, K. (2016). Gestão de recursos hídricos em tempos de crise. Porto Alegre: Artmed, 228.

Rasella, D (2013). Impacto do Programa Água para Todos (PAT) sobre a morbi-mortalidade por diarreia em crianças do Estado da Bahia, Brasil. Cad. Saúde Pública, Rio de Janeiro, 29(1), 40-50.

Santos, R. N. (2011). Teor de sódio e outros íons em águas subterrâneas do município de Rosário (MA) e suas possíveis implicações na saúde da população. 2011. Dissertação (Mestrado em Saúde e Ambiente) Universidade Federal do Maranhão, São Luís.

World Health Organization - WHO 920130. Water supply, sanitation and hygiene development. 